\title{
Curcumol attenuates epithelial-mesenchymal transition of nasopharyngeal carcinoma cells via TGF-ß1
}

\author{
DAZHONG YAN ${ }^{1}$, SHISHAN DENG ${ }^{2}$, WEIGANG GAN ${ }^{1}$, SIJUN LI $^{1}$ and YUANQUAN LI ${ }^{1}$ \\ ${ }^{1}$ Department of Otolaryngology, Affiliated Hospital of North Sichuan Medical College; \\ ${ }^{2}$ Department of Human Anatomy Teaching and Research, North Sichuan Medical College, Nanchong, Sichuan 637000, P.R. China
}

Received September 27, 2017; Accepted December 15, 2017

DOI: $10.3892 / \mathrm{mmr} .2018 .8817$

\begin{abstract}
The current study aimed to identify the effect and primary mechanism of Curcumol on the migration of nasopharyngeal carcinoma (NPC) cells in vitro and in vivo. Curcumol was dissolved in absolute ethyl alcohol and the experiment was performed in NPC 5-8F cells in vitro and in vivo. The effect of different concentrations of Curcumol on cell migration was determined using wound healing and Transwell assays. A cell counting kit-8 (CCK-8) assay was also performed in order to determine cell viability. Flow cytometry was used to detect the effect of Curcumol on apoptosis. The expression of epithelial-mesenchymal transition (EMT)-associated proteins and genes was evaluated by western blotting, reverse transcription-quantitative polymerase chain reaction (RT-qPCR) and ELISA. In addition, the antitumor activity of Curcumol was investigated in female BALB/C nude mice with orthotopic tumor implants. The results indicated that cell apoptosis was increased and the viability of NPC 5-8F cells was decreased following treatment with Curcumol at doses of $0.1,0.2$ and $0.4 \mu \mathrm{M} / \mathrm{ml}$. The results of in vivo experiments indicated that tumor growth and weight were decreased following Curcumol administration. Furthermore, the results of western blotting and RT-qPCR demonstrated that Curcumol altered the level of E-cadherin and $\mathrm{N}$-cadherin in a dose-dependent manner in vivo. Curcumol also regulated the secretion of protein markers in the serum that were associated with EMT and TGF- $\beta 1$ in the $5-8 \mathrm{~F}$ xenograft mouse model. Thus, the results indicated that Curcumol induced TGF- $\beta 1$-mediated EMT arrest by regulating E-cadherin and $\mathrm{N}$-cadherin, which may prevent further development of NPC.
\end{abstract}

Correspondence to: Professor Dazhong Yan, Department of Otolaryngology, Affiliated Hospital of North Sichuan Medical College, 63 Wenhua Road, Nanchong, Sichuan 637000, P.R. China E-mail: docyandazhong@163.com

Key words: Curcumol, transforming growth factor- $\beta 1$, metastasis, nasopharyngeal carcinoma

\section{Introduction}

Nasopharyngeal carcinoma (NPC) primarily occurs in the epithelial lining of the nasopharynx and is one of the primary head and neck tumor types (1). It is prevalent in Southern China and East Asia, Greenland (native), Canada (Northwest Territories), and Alaska $(2,3)$. The health status of patients under intensity-modulated radiation therapy and concurrent chemoradiotherapy were improved, however, the prognosis of patients with NPC with distant metastasis remains poor (4). Therefore, further investigation of the molecular mechanisms of NPC metastasis and development of effective treatment strategies is required in order to develop individualized treatment for patients with the disease.

A previous study demonstrated that cancer-associated mortalities caused by malignant tumors are associated with metastasis (5). The tumor cell microenvironment serves a role during tumor progression, including metastasis (6). Transforming growth factor- $\beta$ (TGF- $\beta$ ) is a key cytokine in the tumor microenvironment, which serves an important regulatory role in tumorigenesis and development (7). The best-known epithelial-mesenchymal transition (EMT) pathway is induced by TGF- $\beta$ and causes epithelial cells to generate mesenchymal phenotypes and subsequently enables them to promotes their development $(8,9)$. It has been demonstrated that an increase in the expression of miR-9-3p suppresses the metastasis of NPC via inhibition of the EMT process, thereby providing a series of therapeutic targets for the treatment of NPC (10). Pigment epithelium-derived factor functions as a tumor-suppressor gene in the occurrence of EMT and metastasis in NPC (11). Thus, investigation of therapeutic approaches targeting EMT pathways may be promising for patients with NPC.

Traditional Chinese medicine (TCM) has been used for the treatment of cancer for more than 2,000 years (12). Curcumol is extracted from the roots of the medicinal plant Rhizoma curcumae as a guaiane-type sesquiterpenoid hemiketal (13). There is a previous study on tumor treatment in clinical or scientific research focusing on TCM treatment with low toxicity and drug resistance (14). Previous studies have also demonstrated that Curcumol possesses antitumor, anti-hepatic fibrosis, antiproliferation, anti-inflammatory, antioxidant and antimicrobial activities $(15,16)$. In addition, Curcumol suppresses human cancer cell growth and promotes apoptosis activity in several types of cancer, including cervical 
cancer, breast cancer, lung cancer, gastric cancer and hepatocarcinoma (17,18). Chen et al (19) demonstrated that Curcumol induces HSC-T6 apoptosis at a concentration of $300 \mu \mathrm{M}$ and has few side effects on normal liver cell line BRL-3A. Although Curcumol exhibits antitumor activity, the mechanism of action remains unknown. Furthermore, the effect of Curcumol on the occurrence and development of NPC remains unclear. Therefore, the current study investigated the effect of Curcumol on NPC with regards to metastasis.

\section{Materials and methods}

Cell culture and animals. All experiments were performed in the Central Laboratory of the North Sichuan Medical College (Sichuan, China). Human NPC 5-8F cells were provided by the Shanghai Institute for Biological Sciences (Shanghai, China). Cells were cultured in RPMI 1640 medium (Hyclone; GE Healthcare Life Sciences, Logan, UT, USA) with $10 \%$ fetal bovine serum (FBS; Hyclone; GE Healthcare Life Sciences) and maintained with $5 \% \mathrm{CO}_{2}$ at $37^{\circ} \mathrm{C}$. A total of 20 female BALB/C athymic nude mice, aged 4-6 weeks and weighing 18-20 g, were purchased from the Institute of Zoology, Chinese Academy of Sciences (Beijing, China) and housed in a sterile environment at $25^{\circ} \mathrm{C}$ with a 12-h light/dark cycle and $40 \%$ humidity, and food and water sterilized by high pressure used to feed the mice ad libitum. Curcumol was dissolved to a concentration of $10 \mathrm{mg} / \mathrm{ml}$ in absolute ethyl alcohol and then diluted with the 10\% FBS RPMI-1640 medium (adjustment based on the required concentration of the drug). Cells without Curcumol treatment $(0 \mu \mathrm{M} / \mathrm{ml})$ served as a control group. Animal experiments were approved by the Affiliated Hospital of North Sichuan Medical College ethics committee (CBYXY0022).

Drugs and reagents. Curcumol (cat. no. 100185-200506) was purchased from MedChemExpress (Monmouth Junction, NJ, USA). A cell counting kit-8 (CCK-8) assay kit was obtained from Dojindo Molecular Technologies, Inc. (Kumamoto, Japan). Dimethyl sulfoxide (DMSO) was purchased from Beyotime Institute of Biotechnology (Haimen, China) and used for the storage of cells. The purified recombinant human TGF- $\beta 1$ powder (R\&D Systems, Inc., Minneapolis, MN USA) was dissolved in $4 \mathrm{mM} \mathrm{HCl}$ containing $1 \mathrm{mg} / \mathrm{ml}$ bovine serum albumin (Shanghai Yi Sheng Biotechnology Co., Ltd., Shanghai, China; storage concentration: $50 \mathrm{ng} / \mathrm{ml}$ ). Curcumol was diluted with media to different concentrations prior to use. Matrigel was purchased from BD Biosciences (Franklin Lakes, NJ, USA). Transwell inserts were provided by Corning Costar Co., Ltd. (Corning, NY, USA). Rabbit polyclonal antibodies against E-cadherin (cat. no. 3195), N-cadherin (cat. no. 13116) and $\beta$-actin (cat. no. 3700) were purchased from Cell Signaling Technology, Inc. (Danvers, MA, USA). Goat anti-TGF- $\beta 1$ (cat. no. TA130016), rabbit monoclonal antibody for $\beta$-actin (cat. no. TA130008), horseradish peroxidase (HRP)-conjugated goat anti-mouse (cat. no. TA130010) and goat anti-rabbit (cat. no. TA130020) immunoglobulin G were purchased from OriGene Technologies, Inc. (Rockville, MD, USA). The enhanced chemiluminescence (ECL) reagent was purchased from EMD Millipore (Billerica, MA, USA). The reagents for quantitative polymerase chain reaction (qPCR) were obtained from Takara Biotechnology Co., Ltd. (Dalian, China). Other chemicals were of standard analytical grade.

Curcumol treatment in vitro. RPMI-1640 culture medium without FBS was used as the primary solvent with the following treatments: i) Control group, cells without Curcumol $(0 \mu \mathrm{M} / \mathrm{ml})$ treatment; ii) $0.1 \mu \mathrm{M} / \mathrm{ml}$ Curcumol group; iii) $0.2 \mu \mathrm{M} / \mathrm{ml}$ Curcumol group; iv) $0.4 \mu \mathrm{M} / \mathrm{ml}$ Curcumol group. Following mixing of the medium, serum and Curcumol according to the concentration requirement, cells were cultured in $37^{\circ} \mathrm{C}$ with $5 \% \mathrm{CO}_{2}$.

Cell viability assay. Cell viability was detected using a CCK-8 assay. Cells were seeded in $100 \mu \mathrm{l}$ complete medium in 96-well plates at a density of $5 \times 10^{5} / \mathrm{ml}$ and triplicate wells were used for each group. Following $8 \mathrm{~h}$ incubation at $37^{\circ} \mathrm{C}$, cells were exposed to different doses of Curcumol for $48 \mathrm{~h}$ in 96 -well plates. A solution of $10 \mu \mathrm{l} \mathrm{CCK-8}$ and $90 \mu \mathrm{l} \mathrm{FBS-free} \mathrm{medium}$ was added to each well and incubated for a further $10 \mathrm{~min}$ at $37^{\circ} \mathrm{C}$. A wavelength of $450 \mathrm{~nm}$ was then used to measure cell viability.

Apoptosis detected by flow cytometry (FCM). Curcumolinduced cell apoptosis was detected by FCM using an Annexin V-fluorescein isothiocyanate (FITC) apoptosis detection kit (Beyotime Institute of Biotechnology). Briefly, following conditions of cell culture described above, all cells were harvested and washed with cold PBS twice and then treated with different concentrations of Curcumol for $48 \mathrm{~h}$ at $37^{\circ} \mathrm{C}$. Cells were stained with Annexin propidium iodide and V-FITC following centrifugation $\left(100 \mathrm{x}\right.$ g for $5 \mathrm{~min}$ at $25^{\circ} \mathrm{C}$ ) and using a flow cytometer and BD CellQuest Pro software version 5.1 (BD Biosciences, Franklin Lakes, NJ, USA).

Cell invasion and migration assay. A wound-healing assay was performed using $5-8 \mathrm{~F}$ treated cells. A total of $8 \times 10^{5}$ cells were incubated in 6-well plates and grown to confluence. An artificial homogenous wound was created in the cell monolayer with a sterile $100 \mu \mathrm{l}$ tip and was then washed with PBS to remove cell debris. Cells were then treated with different concentrations of Curcumol for 24 and $48 \mathrm{~h}$. The wound healing rate following treatment was evaluated using ImageJ software version k1.45 (National Institutes of Health, Bethesda, MD, USA). Transwell chambers ( $8 \mu \mathrm{m}$ pore size; EMD Millipore) with Matrigel were used to detected cell invasion. Cells $\left(1 \times 10^{4}\right)$ were treated with Curcumol for $48 \mathrm{~h}$ and were then plated in the top chambers with an $8 \mu \mathrm{m}$ membrane pore in FBS-free medium. The medium in the bottom chamber was supplemented with $10 \% \mathrm{FBS}$ to allow for invasion for $24 \mathrm{~h}$ at $37^{\circ} \mathrm{C}$. At the end of the experiment, cells at the bottom of the membrane were fixed in $4 \%$ paraformaldehyde for $10 \mathrm{~min}$ at $37^{\circ} \mathrm{C}$ and stained with $1 \%$ crystal violet at $25^{\circ} \mathrm{C}$ (Sigma-Aldrich; Merck KGaA, Darmstadt Germany) for $10 \mathrm{~min}$. Images were captured using a light microscope at a magnification of $x 100$. The specific number of cells per filter in five predetermined fields was then counted and analyzed.

Reverse transcription-qPCR (RT-qPCR). Total RNA was extracted from 5-8F cells using TRIzol (Invitrogen; Thermo Fisher Scientific, Inc., Waltham, MA, USA), according to the 
manufacturer's protocol. RNA was then reverse transcribed into cDNA using an M-MLV kit (Takara Biotechnology Co., Ltd.). All PCR primers were as follows: E-cadherin, forward, 5'-GGT TATTCCTCCCATCAGCT-3' and reverse, 5'-CTTGGCTGA GGAGGGTGTA-3'; N-cadherin, forward, 5'-GGTGGAGGA GAAGAAGACCAG-3' and reverse, 5'-GGCATCAGGCTC CACAGT-3'; GAPDH, forward, 5'-TTCGTCATGGGTGTG AAC-3' and reverse, 5'-AGTGAGCTTCCCGTTCAGC-3'. The qPCR assay $\left(95^{\circ} \mathrm{C}\right.$ for $30 \mathrm{sec}$, then 40 cycles of $95^{\circ} \mathrm{C}$ for $5 \mathrm{sec}$ and $60^{\circ} \mathrm{C}$ for $30 \mathrm{sec}$ ) was performed as the instruction in triplicate using SYBR Green PCR Master mix and Applied Biosystems Prism 7500 (Applied Biosystems; Thermo Fisher Scientific, Inc.). The relative fold change among groups was analyzed using $2^{-\Delta \Delta \mathrm{Cq}}$ quantitative analysis (20).

Western blot analysis. Cells treated with Curcumol were lysed in radioimmunoprecipitation lysis buffer (Beyotime Institute of Biotechnology) on ice for $30 \mathrm{~min}$. Cells were then centrifuged at $100 \mathrm{x} \mathrm{g}$ for $15 \mathrm{~min}$ at $4^{\circ} \mathrm{C}$ and the protein concentration was determined using a BCA protein assay kit (Beyotime Institute of Biotechnology). Equal amounts $(25 \mu \mathrm{g})$ of total protein samples were separated using 10\% SDS-PAGE and different protein bands were transferred to polyvinylidene fluoride membranes (EMD Millipore). Membranes were blocked using $0.1 \%$ TBST with 5\% non-fat dry milk at room temperature for $1 \mathrm{~h}$ and incubated with E-cadherin (dilution: 1:1,000), $\mathrm{N}$-cadherin (dilution: 1:1,000) and anti- $\beta$-actin (dilution: $1: 4,000)$ at $4^{\circ} \mathrm{C}$ overnight. Membranes were then washed using $0.1 \%$ TBST four times and incubated with HRP-conjugated secondary antibodies for $1.5 \mathrm{~h}$ at room temperature. The target protein was detected by ECL and the bands were quantified using ImageJ software version k1.45.

ELISA. Pretreated serum samples and cell supernatants were dissolved on ice and a TGF- $\beta 1$ ELISA kit (cat. no. ab100647; Abcam, Cambridge, UK) was used to measure the TGF- $\beta 1$ concentrations in accordance with the manufacturer's protocols. Each sample was run in triplicate. Standards, serum samples or cell supernatants were added to 96-well plates, respectively. Subsequently, the enzyme conjugation solutions were added and the mixtures were co-incubated for $60 \mathrm{~min}$ at $37^{\circ} \mathrm{C}$. Every well was washed 5 times with wash buffer. Substrate I and II were then added to each well respectively and the plate was kept away from light at room temperature for $15 \mathrm{~min}$. The plate was then read at a wavelength of $450 \mathrm{~nm}$ using an ELISA reader.

Xenograft tumor models. NPC 5-8F cells $\left(1 \times 10^{7}\right)$ were resuspended with $200 \mu \mathrm{l}$ PBS and Matrigel and subcutaneous injections were performed on both sides of the nude mice following anesthesia with ether. Mice were randomly assigned to a control group and a treated group when the tumors reached an average volume of $50 \mathrm{~mm}^{3}$ (volume=length $\mathrm{x}$ width $2 / 2$ ). The treated group were administered with Curcumol at $15 \mu \mathrm{g} / \mathrm{kg}$ crude drug (sterile water solution, equivalent to the human dosage) by gavage twice a day for 35 days and the control group mice were given an equal volume of sterile water. The tumor volume was measured every 7 days. Mice were sacrificed by cervical dislocation and tumors and peripheral blood were collected. Following weighing of the tumor, the tumors were stored at $-8^{\circ} \mathrm{C}$. In addition, blood samples were centrifuged at $100 \mathrm{x} \mathrm{g}$ for $15 \mathrm{~min}$ at $25^{\circ} \mathrm{C}$ in order to obtain the serum and were then stored at $-80^{\circ} \mathrm{C}$.

Statistical analysis. Data are presented as the mean \pm standard error of the mean. Each experiment was repeated at least three times. Data were analyzed using SPSS 13.0 (SPSS Inc., Chicago, IL, USA). A Student's t-test was used to analyze differences between two groups, while the differences between $>2$ groups were detected using one-way analysis of variance followed by Student-Newman-Keuls test. $\mathrm{P}<0.05$ was considered to indicate a statistically significant difference.

\section{Results}

Curcumol suppresses NPC cell proliferation and promotes $N P C$ cell apoptosis. The effect of Curcumol on NPC $5-8 \mathrm{~F}$ cell viability was investigated by determining the growth of 5-8F cells using a CCK-8 assay. The results demonstrated that Curcumol significantly inhibited cell growth at doses of 0.1 , 0.2 and $0.4 \mu \mathrm{M} / \mathrm{ml}$ (Fig. 1A). 5-8F cell apoptosis was quantified using FCM. The results indicated that the rate of apoptosis was significantly increased following Curcumol treatment in a dose-dependent manner (Fig. 1B and C).

Curcumol inhibits 5-8F cell invasion and migration. A wound-healing assay and Transwell assays were performed to investigate whether Curcumol treatment affected the migration and invasion ability of NPC cells (Fig. 2). The migration ability of cells was significantly decreased with an increase of the concentration of Curcumol compared with that in the control group (Fig. 2A and C). Cell invasion was significantly decreased in a dose-dependent manner at different concentrations of Curcumol treatment (Fig. 2B and D).

Effect of Curcumol on expression of EMT-associated genes. The mechanism of action of Curcumol on inhibition of $5-8 \mathrm{~F}$ cell development was investigated by performing RT-qPCR and western blotting (Fig. 3). The results of RT-qPCR suggested that the expression of E-cadherin mRNA was significantly increased in $5-8 \mathrm{~F}$ cells treated with Curcumol at doses of $0.1,0.2$ and $0.4 \mu \mathrm{M} / \mathrm{ml}$ (Fig. 3A). By contrast, the expression of $\mathrm{N}$-cadherin was significantly inhibited in $5-8 \mathrm{~F}$ cells treated with Curcumol in a dose-dependent manner (Fig. 3B). The results of western blotting were consistent with this (Fig. 3C-F). Thus, this suggests that Curcumol may regulate EMT-associated proteins in a dose-dependent manner.

Curcumol inhibits the growth of transplanted tumors with $5-8 F$ cells in vivo. Based on the results of experiments on $5-8 \mathrm{~F}$ cells, further investigation was performed into the effect of Curcumol on NPC in vivo. The results indicated that the tumor volume of the Curcumol group on day 35 was significantly decreased compared with that in the control group (Fig. 4A and B). The tumor weight of the control group was also significantly increased compared with that in the Curcumol group (Fig. 4C), suggesting that Curcumol significantly inhibited the growth of tumors in vivo. 

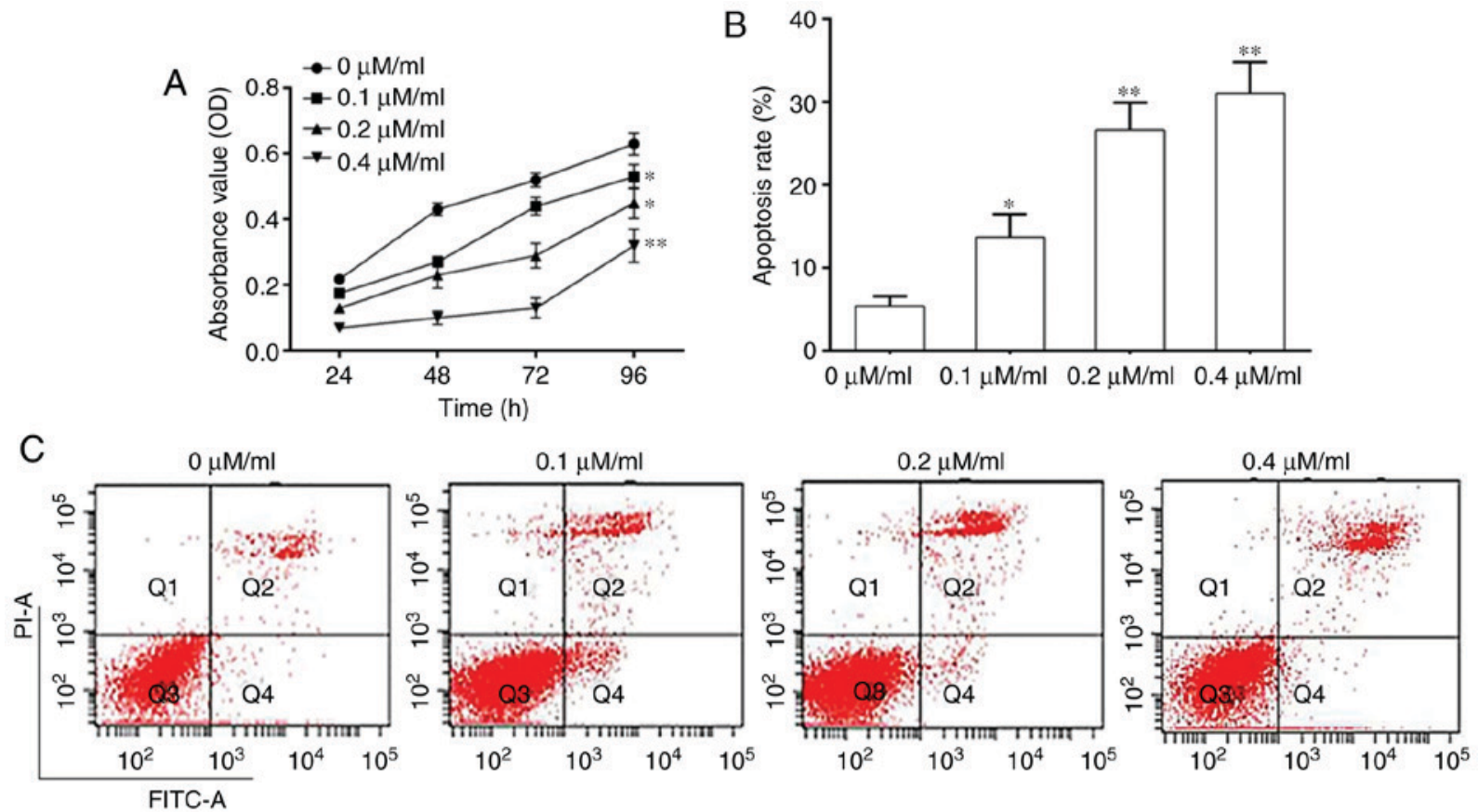

Figure 1. Curcumol inhibited the viability of NPC cells. (A) NPC cell viability. (B) Apoptosis rate of NPC cells. (C) Flow cytometry analysis of NPC cell apoptosis. Values are presented as mean \pm standard error of the mean. ${ }^{*} \mathrm{P}<0.05,{ }^{* *} \mathrm{P}<0.01$, vs. $0 \mu \mathrm{M} / \mathrm{ml}$. NPC, nasopharyngeal carcinoma; OD, optical density; PI, propidium iodide; FITC, fluorescein isothiocyanate.

A
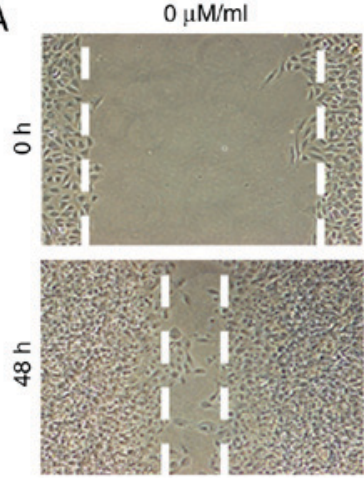

B

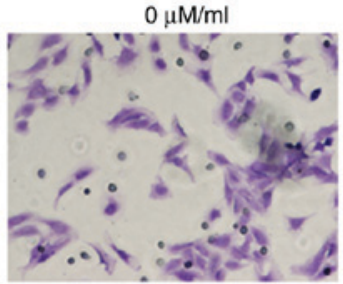

C

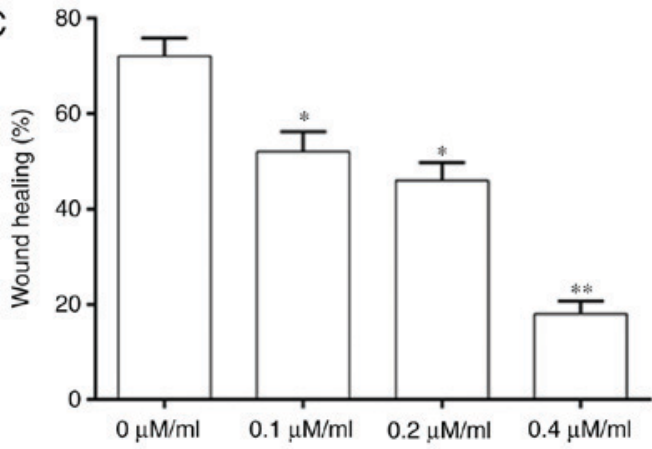

$0.1 \mu \mathrm{M} / \mathrm{ml}$

$0.1 \mu \mathrm{M} / \mathrm{ml}$
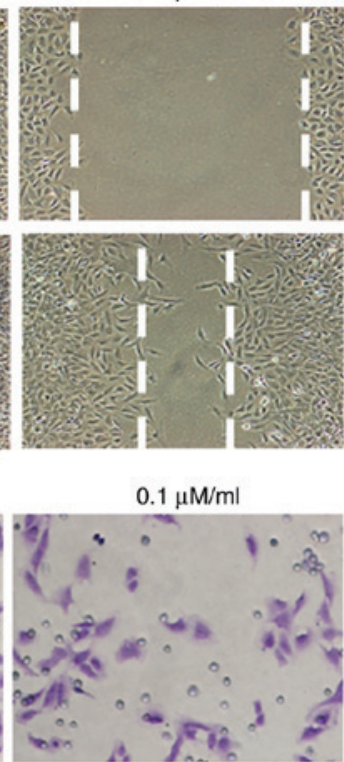

$\mathrm{D}$

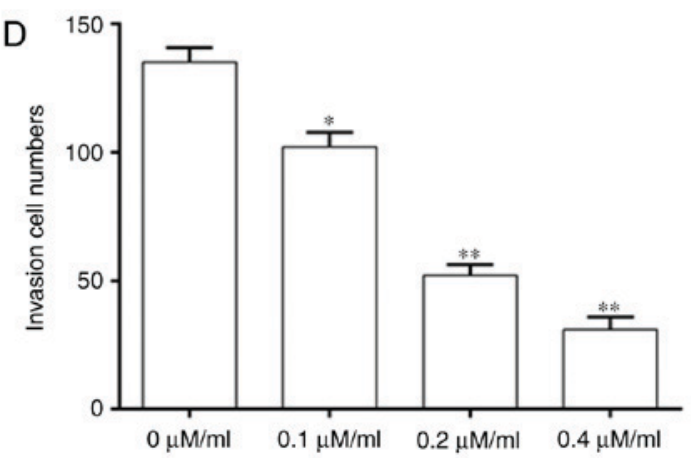

Figure 2. Curcumol inhibited the invasion and migration ability of NPC cells. (A) Migration ability of NPC cells. (B) Invasion ability of NPC cells. (C) Quantification of migration ability of NPC cells. (D) Quantification of invasion ability of NPC cells. Values are presented as the mean \pm standard error of the mean. ${ }^{*} \mathrm{P}<0.05,{ }^{* *} \mathrm{P}<0.01$, vs. $0 \mu \mathrm{M} / \mathrm{ml}$. NPC, nasopharyngeal carcinoma. 

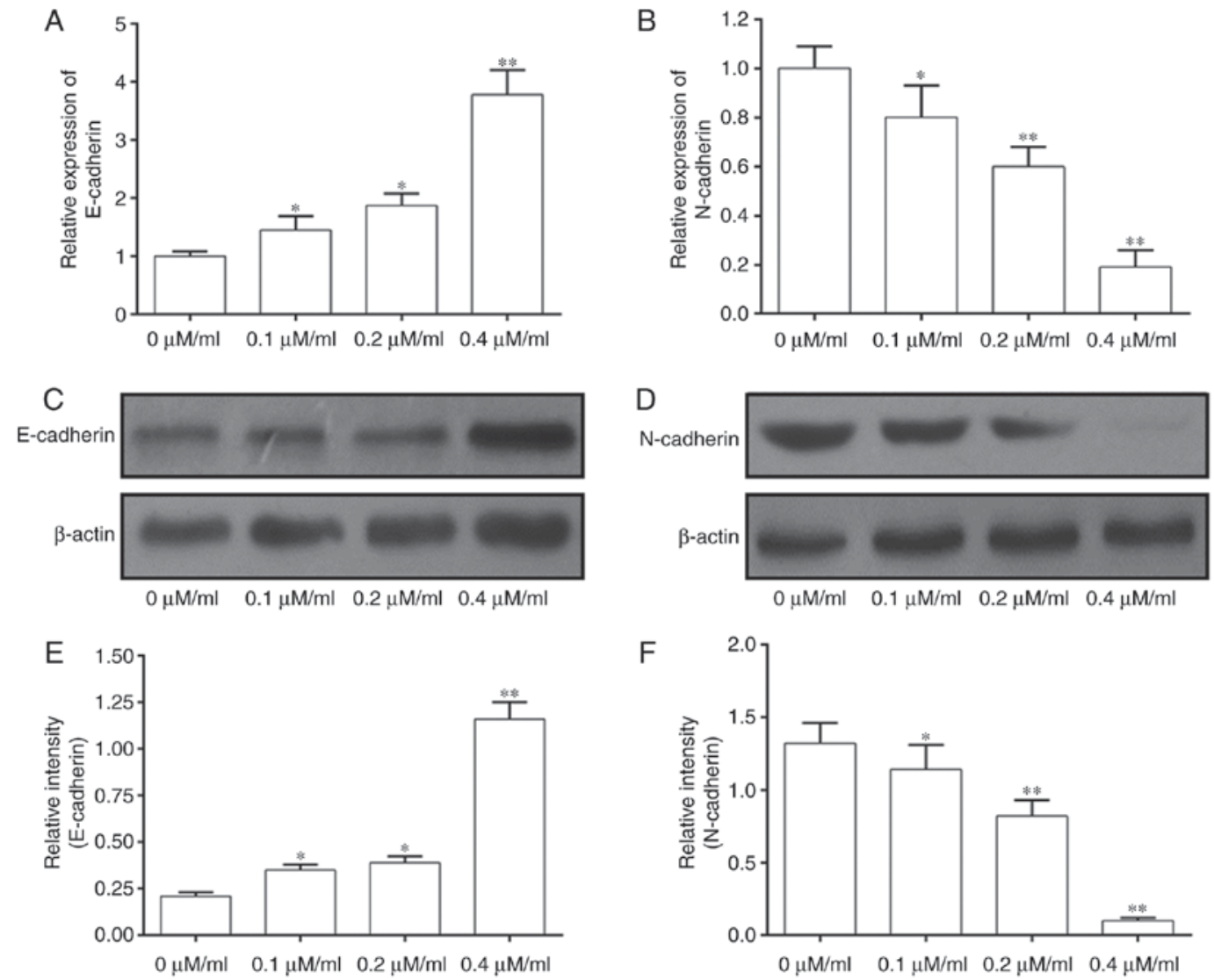

Figure 3. Curcumol altered the expression levels of genes in the EMT pathway. (A) Expression of E-cadherin mRNA. (B) Expression of N-cadherin mRNA. (C) Western blot analysis of the expression of E-cadherin protein. (D) Western blot analysis of the expression of N-cadherin protein. (E) Quantification of the expression of E-cadherin protein. (F) Quantification of the expression of $\mathrm{N}$-cadherin protein. Values are presented as the mean \pm standard error of the mean. ${ }^{*} \mathrm{P}<0.05,{ }^{* *} \mathrm{P}<0.01$, vs. $0 \mu \mathrm{M} / \mathrm{ml}$. EMT, epithelial mesenchymal transition.

A

Control $(0 \mu \mathrm{M} / \mathrm{ml})$

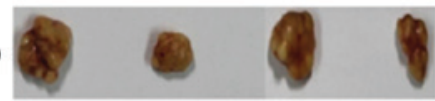

Curcumol $(0.4 \mu \mathrm{M} / \mathrm{ml})$
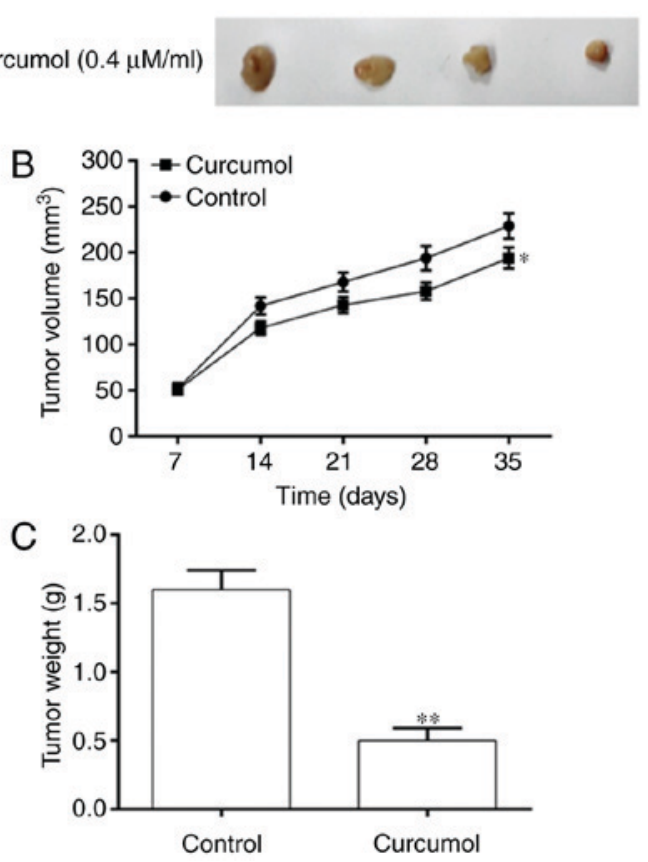

Figure 4. Curcumol attenuated cancer progression in vivo. (A) Tumors removed from nude mice. (B) Tumor volume in the Curcumol and control groups. (C) Tumor weight in the Curcumol and control groups. Values are presented as the mean \pm standard error of the mean. ${ }^{*} \mathrm{P}<0.05,{ }^{* *} \mathrm{P}<0.01$, vs. control group.
Curcumol effected the expression of EMT-associated genes and the secretion of TGF- $\beta 1$ in vivo. Tumors and serum were extracted from nude mice and western blotting and ELISA assays were performed to detect the expression of EMT-associated proteins and the secretion of TGF- $\beta 1$. The expression of E-cadherin was significantly increased in the Curcumol group compared with the control group (Fig. 5A), while the expression of $\mathrm{N}$-cadherin was significantly decreased in the Curcumol group (Fig. 5B). The expression of TGF- $\beta 1$ in tumors and serum was measured by western blotting and ELISA. The concentration of TGF- $\beta 1$ was significantly decreased in the Curcumol group compared with the control group (Fig. 5C) and the results of tumor analysis were consistent with this (Fig. 5D).

\section{Discussion}

NPC is the most common malignant tumor of the nasopharynx mucosa and has regional distribution characteristics; the incidence in developing countries is higher compared with developed countries (21). The application of intensity-modulated radiotherapy and platinum-based chemotherapy, which are used alone or in combination, has led to significant improvements in tumor control and long-term survival of patients with NPC (22). However, metastasis remains an important factor in the treatment and prognosis of patients with NPC (23). TCM has been developed for cancer research 
A
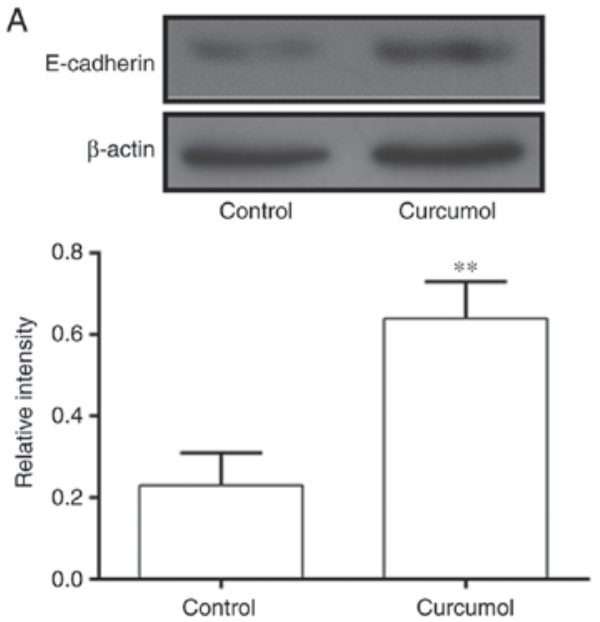

C
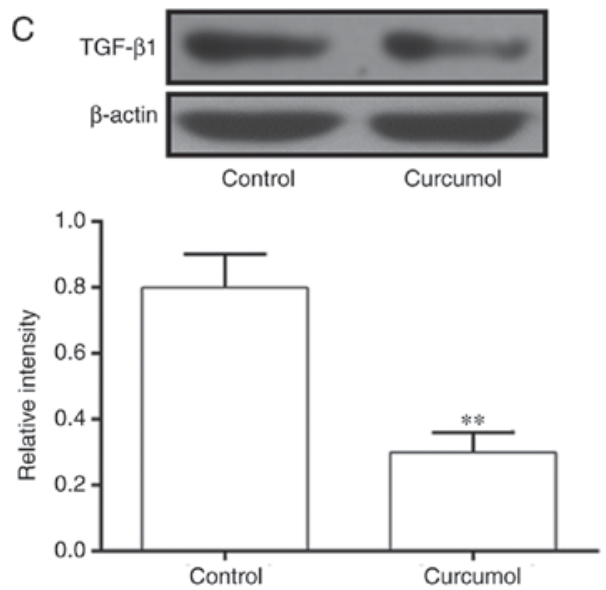

B
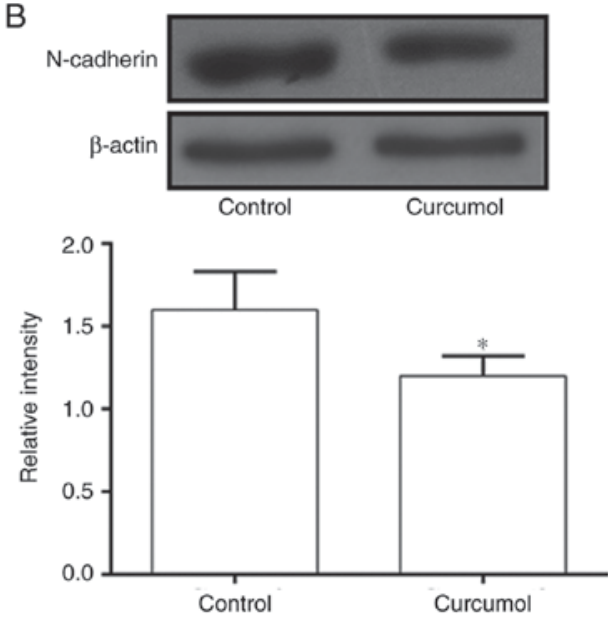

D

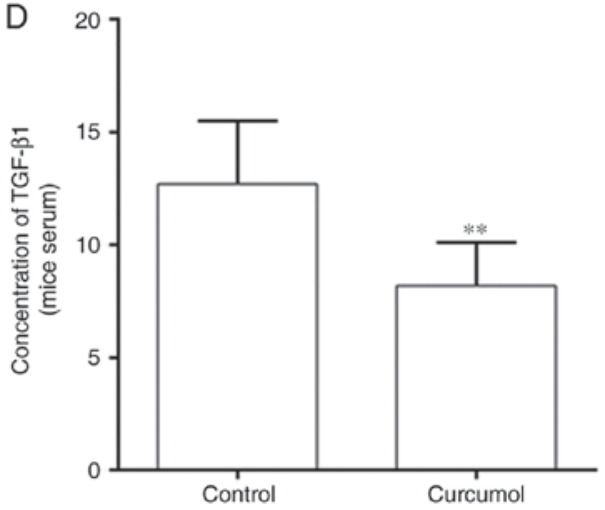

Figure 5. Curcumol altered the expression levels of genes in the EMT pathway in vivo. (A) Expression of E-cadherin indicated using western blotting. (B) Expression of N-cadherin indicated using western blotting. (C) Expression of TGF- $\beta 1$ indicated using western blotting. (D) Secretion of TGF- $\beta 1$ in the serum of transplanted tumor models in nude mice. Values are presented as the mean \pm standard error of the mean. $\mathrm{P}<0.05$, ${ }^{* *} \mathrm{P}<0.01$, vs. control group. EMT, epithelial mesenchymal transition; TGF- $\beta 1$, transforming growth factor- $\beta 1$.

and many Chinese herbal medicines have been demonstrated to inhibit cancer. Celastrol is a triterpene from TCM, which demonstrates anti-proliferative activity in HONE-1 and NPC-039 cell lines and induces apoptosis through the death receptor and mitochondrial pathway in human NPC cells, which makes it a promising candidate in the development of drugs for treating NPC (24). Evodiamine inhibits the migration and invasive ability of NPC cells and metastasis targeting matrix metalloproteinase-2 (25). The aim of the current study was to identify a Chinese herbal medicine that targets the EMT pathway in order to inhibit metastasis of NPC.

EMT is one of the key factors serving a role in tumor progression (26). It is a biological process in which epithelial cells lose their epithelial morphology, thereby improving their migration and invasive ability and giving them status as mesenchymal cells (27). Thus, this suggests that the EMT pathway is vital in the invasion and metastasis ability of malignant tumors (28). It has been suggested that TGF- $\beta 1$ is the most important factor in the induction of EMT during development, cancer and other pathological conditions (26). It has also been previously demonstrated that in HepG2 cell lines, simple TGF- $\beta 1$ stimulation induces EMT (29). In addition, the molecular hallmarks of EMT are mesenchymal and epithelial phenotypes, including the expression of E-cadherin and N-cadherin (30). The metastasis of NPC is closely associated with the occurrence of EMT and previous study has indicated that inhibition of EMT may significantly suppress metastasis of NPC (25). Therefore, investigation of EMT-associated medicine is required to improve the prognosis of patients with NPC.

Due to the lack of side effects, an increasing number of studies have focused on the biological activities of Curcumol. Curcumol exhibits multiple biological activities, including antitumor activity (31). In addition, the mechanism of the anticancer activity of Curcumol was by inducing the expression of anti-oncogenes or inhibiting the expression of oncogenes. The results of the current study indicated that the viability of NPC 5-8F cells was significantly decreased following treatment with Curcumol and the rate of apoptosis was significantly increased in a dose-dependent manner, which provides basis for further study of the effect of Curcumol on NPC. The results of the wound-healing and Transwell assays confirmed that Curcumol reduced the migration and invasion ability of 5-8F cells. Furthermore, the expression of the primary regulatory proteins serving a role in the EMT pathway are also regulated by Curcumol. The results of the in vivo experiments also indicated that Curcumol 
significantly inhibited tumor growth and the inhibitory effect of the $0.4 \mu \mathrm{M} / \mathrm{ml}$ group was significantly higher compared with that of the control group. Furthermore, the results of in vivo experiments investigating the expression of EMT associated proteins were consistent with those on 5-8F cells. In addition, Curcumol inhibited the expression of TGF- $\beta 1$ in tumors in nude mice and also inhibits the secretion of TGF- $\beta 1$ in the serum of nude mice.

In conclusion, the current study investigated the effect of Curcumol in arresting cell migration against the human NPC5-8F cell line and also showed that the inhibition of TGF- $\beta 1$ led to the decrease of EMT occurrence, which was considered a result of the anticancer activity of Curcumol. These results were also confirmed in vivo using a xenograft mouse model.

However, there are some limitations to the current study. Due to the funding of the project and the time schedule of the authors, only one cell line was selected for the experiment. Therefore, further studies using a greater number of cell lines are required to supplement the experimental results. However, the results of the current study did indicate the molecular mechanism of Curcumol, which may potentially improve the quality of life of patients with NPC in the future.

\section{Acknowledgements}

Not applicable.

\section{Funding}

This study was funded by Sichuan Provincial Science and Technology Department of key projects (14ZA0198).

\section{Availability of data and materials}

The datasets used and/or analyzed during the current study are available from the corresponding author on reasonable request.

\section{Authors' contributions}

DY did the majority of the experiments and wrote the paper. SD, WG, SL and YL helped perform the cell experiments. DY performed the statistical analysis.

\section{Ethics approval and consent to participate}

Animal experiments were approved by Affiliated Hospital of North Sichuan Medical College hospital ethics committee (CBYXY0022). All procedures performed in studies were in accordance with the ethical standards.

\section{Consent for publication}

Not applicable.

\section{Competing interests}

The authors declare that they have no competing interests.

\section{References}

1. Hu C, Wei W, Chen X, Woodman CB, Yao Y, Nicholls JM, Joab I, Sihota SK, Shao JY, Derkaoui KD, et al: A global view of the oncogenic landscape in nasopharyngeal carcinoma: An integrated analysis at the genetic and expression levels. PLoS One 7: e41055, 2012.

2. Liu N, Chen NY, Cui RX, Li WF, Li Y, Wei RR, Zhang MY, Sun Y, Huang BJ, Chen M, et al: Prognostic value of a microRNA signature in nasopharyngeal carcinoma: A microRNA expression analysis. Lancet Oncol 13: 633-641, 2012.

3. Sarmiento MP and Mejia MB: Preliminary assessment of nasopharyngeal carcinoma incidence in the Philippines: A second look at published data from four centers. Chin J Cancer 33: 159-164, 2014.

4. Wang HZ, Cao CN, Luo JW, Yi JL, Huang XD, Zhang SP, Wang K, Qu Y, Xiao JP, Li SY, et al: High-risk factors of parotid lymph node metastasis in nasopharyngeal carcinoma: A case-control study. Radiat Oncol 11: 113, 2016.

5. Yousefi M, Bahrami T, Salmaninejad A, Nosrati R, Ghaffari P and Ghaffari SH: Lung cancer-associated brain metastasis: Molecular mechanisms and therapeutic options. Cell Oncol (Dordr) 40: 419-441, 2017.

6. Wu D: Innate and adaptive immune cell metabolism in tumor microenvironment. Adv Exp Med Biol 1011: 211-223, 2017.

7. He X, Guo X, Zhang H, Kong X, Yang F and Zheng C: Mechanism of action and efficacy of LY2109761, a TGF- $\beta$ receptor inhibitor, targeting tumor microenvironment in liver cancer after TACE. Oncotarget 9: 1130-1142, 2017.

8. Fuxe J and Karlsson MC: TGF- $\beta$-induced epithelial-mesenchymal transition: A link between cancer and inflammation. Semin Cancer Biol 22: 455-461, 2012.

9. Grelet S, McShane A, Geslain R and Howe PH: Pleiotropic roles of non-coding RNAs in TGF- $\beta$-mediated epithelial-mesenchymal transition and their functions in tumor progression. Cancers (Basel) 9: E75, 2017.

10. Ding Y, Pan Y, Liu S, Jiang F and Jiao J: Elevation of MiR-9-3p suppresses the epithelial-mesenchymal transition of nasopharyngeal carcinoma cells via down-regulating FN1, ITGB1 and ITGAV. Cancer Biol Ther 18: 414-424, 2017.

11. Zhang T, Yin P, Zhang Z, Xu B, Che D, Dai Z, Dong C, Jiang P, Hong H, Yang Z, et al: Deficiency of pigment epithelium-derived factor in nasopharyngeal carcinoma cells triggers the epithelial-mesenchymal transition and metastasis. Cell Death Dis 8: e2838, 2017.

12. Xiao LJ and Tao R: Traditional chinese medicine (TCM) therapy. Adv Exp Med Biol 1010: 261-280, 2017.

13. Wang J, Huang F, Bai Z, Chi B, Wu J and Chen X: Curcumol inhibits growth and induces apoptosis of colorectal cancer LoVo cell line via IGF-1R and p38 MAPK pathway. Int J Mol Sci 16: 19851-19867, 2015 .

14. Mun SH, Kim SB, Kong R, Choi JG, Kim YC, Shin DW, Kang $\mathrm{OH}$ and Kwon DY: Curcumin reverse methicillin resistance in Staphylococcus aureus. Molecules 19: 18283-18295, 2014.

15. Jiang Y, Li ZS, Jiang FS, Deng X, Yao CS and Nie G: Effects of different ingredients of zedoary on gene expression of HSC-T6 cells. World J Gastroenterol 11: 6780-6786, 2005.

16. Dang YY, Li XC, Zhang QW, Li SP and Wang YT: Preparative isolation and purification of six volatile compounds from essential oil of Curcuma wenyujin using high-performance centrifugal partition chromatography. J Sep Sci 33: 1658-1664, 2010.

17. Zhang W, Wang Z and Chen T: Curcumol induces apoptosis via caspases-independent mitochondrial pathway in human lung adenocarcinoma ASTC-a-1 cells. Med Oncol 28: 307-314, 2011.

18. Guo P, Wang YW, Weng BX, Li XK, Yang SL and Ye FQ: Synthesis, anti-tumor activity, and structure-activity relationships of curcumol derivatives. J Asian Nat Prod Res 16: 53-58, 2014.

19. Chen G, Wang Y, Li M, Xu T, Wang X, Hong B and Niu Y: Curcumol induces HSC-T6 cell death through suppression of Bcl-2: Involvement of PI3K and NF-kappaB pathways. Eur J Pharm Sci 65: 21-28, 2014.

20. Livak KJ and Schmittgen TD: Analysis of relative gene expression data using real-time quantitative PCR and the 2(-Delta Delta C(T)) method. Methods 25: 402-408, 2001.

21. Fles R, Bos ACRK, Supriyati, Rachmawati D, Waliyanti E, Tan IB, Haryana SM, Schmidt MK and Dewi FST: The role of Indonesian patients' health behaviors in delaying the diagnosis of nasopharyngeal carcinoma. BMC Public Health 17: 510, 2017. 
22. Twu CW, Wang WY, Chen CC, Liang KL, Jiang RS, Wu CT, Shih YT, Lin PJ, Liu YC and Lin JC: Metronomic adjuvant chemotherapy improves treatment outcome in nasopharyngeal carcinoma patients with postradiation persistently detectable plasma Epstein-Barr virus deoxyribonucleic acid. Int J Radiat Oncol Biol Phys 89: 21-29, 2014

23. Chee J, Loh KS, Tham I, Ho F, Wong LC, Tan CS, Goh BC and Lim CM: Prognostic stratification of patients with metastatic nasopharyngeal carcinoma using a clinical and biochemical scoring system. J Cancer Res Clin Oncol 143: 2563-2570, 2017.

24. Lin HF, Hsieh MJ, His YT, Lo YS, Chuang YC, Chen MK and Chien SY: Celastrol-induced apoptosis in human nasopharyngeal carcinoma is associated with the activation of the death receptor and the mitochondrial pathway. Oncol Lett 14: 1683-1690, 2017.

25. Peng X, Zhang Q, Zeng Y, Li J, Wang L and Ai P: Evodiamine inhibits the migration and invasion of nasopharyngeal carcinoma cells in vitro via repressing MMP-2 expression. Cancer Chemother Pharmacol 76: 1173-1184, 2015.

26. Runa F, Hamalian S, Meade K, Shisgal P, Gray PC and Kelber JA: Tumor microenvironment heterogeneity: Challenges and opportunities. Curr Mol Biol Rep 3: 218-229, 2017.
27. Wu A, Wu K, Li J, Mo Y, Lin Y, Wang Y, Shen X, Li S, Li L and Yang Z: Let-7a inhibits migration, invasion and epithelial-mesenchymal transition by targeting HMGA2 in nasopharyngeal carcinoma. J Transl Med 13: 105, 2015.

28. Taparra K, Tran PT and Zachara NE: Hijacking the hexosamine biosynthetic pathway to promote EMT-mediated neoplastic phenotypes. Front Oncol 6: 85, 2016.

29. Zhang M, Sui C, Dai B, Shen W, Lu J and Yang J: PEG10 is imperative for TGF- $\beta 1$-induced epithelialmesenchymal transition in hepatocellular carcinoma. Oncol Rep 37: 510-518, 2017.

30. Heldin $\mathrm{CH}$, Vanlandewijck M and Moustakas A: Regulation of EMT by TGF $\beta$ in cancer. FEBS Lett 586: 1959-1970, 2012.

31. Lu JJ, Dang YY, Huang M, Xu WS, Chen XP and Wang YT: Anti-cancer properties of terpenoids isolated from Rhizoma Curcumae-a review. J Ethnopharmacol 143: 406-411, 2012.

This work is licensed under a Creative Commons

Attribution-NonCommercial-NoDerivatives 4.0 International (CC BY-NC-ND 4.0) License. 